\title{
Chronic Disease Prevention and the New Public Health
}

\author{
Helen Ann Halpin, PhD, ScM, ${ }^{1}$ \\ Maria M. Morales-Suárez-Varela MD, $\mathrm{PhD}, \mathrm{PhM},{ }^{2}$ \\ José M Martin-Moreno MD, MPH, DrPH ${ }^{3}$
}

\begin{abstract}
Chronic diseases are the major causes of morbidity and mortality across the globe in developed and developing countries, and in countries transitioning from former socialist status. Chronic diseases - including heart disease, cancer, stroke, diabetes, and respiratory diseases - share major risk factors beyond genetics and social inequalities including tobacco use, unhealthy diet, physical inactivity, and lack of access to preventive care. There are evidence-based interventions that are effective in modifying these risks and subsequently preventing disease. Evidence for prevention is strongest for measures aimed at reducing tobacco use and increasing physical activity, while large gaps remain in our knowledge about how to effectively change eating habits and achieve healthy weights in a population. The New Public Health addresses interventions delivered at three levels: 1) at the level of society, where public policy and governmental interventions can change the environment, as well as individual behavior (e.g., regulation of tobacco products and food composition, taxation, redesigning the built environment, banning advertising); 2) at the level of the community, through the activities of local institutions delivered at the population level (e.g., school-based and workplace health promotion, community education, training, and public awareness campaigns); and 3) at the level of the individual, through the provision of clinical preventive services including screening, counselling, chemoprophylaxis, and immunizations (in recognition of the growing evidence that infections cause important chronic diseases). We conclude with a discussion of comprehensive national and international efforts needed to stem the tide of the growing global burden of chronic disease.
\end{abstract}

\footnotetext{
${ }^{1}$ Professor and Director, Center for Health and Public Policy Studies, School Public Health, University of California, Berkeley, California, United States.

${ }^{2}$ Unit of Public Health and Environmental Care, Department of Preventive Medicine, University of Valencia. Valencia; CIBER - Epidemiology and Public Health Spain; Research Foundation. University Hospital Dr. Peset, Valencia, Spain.

${ }^{3}$ Professor of Preventive Medicine and Public Health at the Medical School, University of Valencia, Spain; Senior Strategic Adviser, World Health Organization-Regional Office for Europe.
}

Correspondence: Helen Halpin at email helenhs@berkeley.edu 
Key Words: chronic diseases, European health, prevention, New Public Health, health promotion, public policy, preventive care, risk factors, tobacco, diet, physical activity, obesity, heart disease, cancer, stroke, diabetes, screening, chemoprophylaxis, immunizations

\section{INTRODUCTION}

The impact of chronic conditions has been underappreciated by society and by health systems in terms of its acute social and economic effects on populations. Despite accounting for around 60 percent of all deaths worldwide, chronic diseases are surprisingly neglected on the public health agendas of most nations and regions, particularly in low and middle-income countries (LMICs), where more attention has traditionally been paid to infectious diseases. ${ }^{1}$ Once associated with rich, industrialized nations, chronic diseases are now the leading causes of death in the developing world, as well. ${ }^{2}$ The largest increase in overall disease burden, mainly due to chronic disease, is concentrated in Central Asia. Existing data on mortality, years of life lost (YLL), and Disability Adjusted Life Years (DALYs) reveal a 10 percent rise in the global burden of disease due to chronic diseases in LMICs from 1990 to $2001 .^{3}$

The paradigm of how we view chronic diseases is also shifting. The relationship between chronic diseases and non-communicable diseases has often been confused as synonymous, or at least closely linked; however, this notion is increasingly being exposed as outdated. Today, we know that infectious agents such as human papillomavirus (HPV), hepatitis B virus (HBV), and Helicobacter pylori can cause cancer of the cervix, liver, and stomach, respectively. Moreover, as life expectancies rise in most countries due to better and more available healthcare, chronic disease prevalence is increasing in populations that perhaps would have had shorter life expectancy in the past, presenting new demands for struggling health systems to improve the health of the middle-aged and the elderly. Likewise, our knowledge on how to combat some diseases such as HIV/AIDS, is gradually transforming once fatal infectious diseases into long-term chronic conditions.

These trends, together with the worldwide increase in hypertension and cancer due to population aging and modifications in health behaviors, contribute to the sharp rise in the prevalence of chronic diseases. These pathologies now cause the greatest share of death and disability in the world. In 2005, at least 35 million people of all ages, nationalities, and socioeconomic levels died from heart disease, stroke, cancer, diabetes, respiratory disease, and other chronic diseases. ${ }^{4}$ In this paper, we have 
chosen to focus on three major chronic conditions: cardiovascular disease (CVD) (heart disease and stroke), cancer, and diabetes. Together, these conditions are not only responsible for most chronic disease morbidity, but also around 45 percent of total mortality worldwide.

We describe global trends in chronic disease burden and epidemiology, including those factors in play in increasing or decreasing the incidence, prevalence, and mortality of these broad disease categories. We also review current knowledge of effective preventive strategies, encompassed under the concept of the New Public Health. Traditional public health activities were highly successful in limited areas of sanitary and hygienic activities, surveillance of infectious diseases and clinical interventions (such as vaccinations, and maternal and child health). The New Public Health refers to a more holistic, multidisciplinary, and multi-sectoral approach to improving population health by tackling risk factors at an individual, community, and societal level.

\section{GLOBAL SPREAD OF CHRONIC DISEASE OVER THE PAST TWENTY YEARS}

\section{Cardiovascular Disease}

Approximately 17 million people die annually of CVD, making it the leading cause of death worldwide. However, since 1950, we have made considerable progress in reducing this disease burden. Age-adjusted death rates from CVD in the United States, as in most industrialized nations, have declined 60 percent, representing one of the most important public health achievements of the $20^{\text {th }}$ century. ${ }^{5}$ This progress is due to improved prevention, diagnosis, and treatment, in particular reduced tobacco use among adults, lower levels of blood pressure and blood cholesterol, and widespread use of effective medical treatments. ${ }^{6}$ Paradoxically, however, the burden of disease is still rising. Demographic changes brought on by aging and longer life expectancy result in greater numbers of elderly people, and consequently more deaths due to CVD, despite the improved adjusted mortality rates.

CVD constitutes an even bigger threat in LMICs, where 80 percent of the global disease burden is found. Variations in death rates are marked: they are lower in populations with short life expectancy and begin to rise as the middle class expands. Thus, it is no surprise that the prevalence of these diseases is rising most quickly in Southeast Asia and the Eastern Mediterranean regions. ${ }^{8,9}$ 
Stroke is an important element of CVD morbidity, disability and mortality. However, the burden does not fall evenly throughout all populations. Those who have suffered one stroke are particularly vulnerable to further episodes. Although incidence is higher for men, strokes affect women more seriously. ${ }^{10}$ Furthermore, relatively disadvantaged racial, ethnic, and socioeconomic groups show higher incidence rates. While such variations also occur within countries, the excess burden of stroke mortality is concentrated in Russia and the Newly Independent States, as well as Mongolia, sub-Saharan Africa, China, and India. ${ }^{5}$ Moreover, even where advanced technology and facilities are available, 60 percent of those who suffer a stroke die or become dependent. Given these bleak statistics and the high cost of treatment and long-term care, preventive strategies, such as prevention and control of hypertension, are our most effective tools in fighting this disease. ${ }^{11}$

Indeed, hypertension - a major risk factor for CVD and other pathologies - constitutes a heavy social and economic burden because it directly contributes to the loss of DALYs for citizens and represents considerable healthcare expenditures for society ${ }^{12}$; untreated hypertension shortens life expectancy by approximately five years..$^{13}$ Despite therapeutic advances, prevalence is increasing worldwide ${ }^{14}$ as is the number of people with uncontrolled high blood pressure. ${ }^{15}$ In 2000, over a quarter of the world's adult population had hypertension, and the proportion is expected to increase to 29 percent by $2025 .{ }^{16}$ While population aging is a significant factor in this rise, it is an incomplete explanation of why mortality and disease burden are increasing. Rodgers and colleagues have noted that up to 43 percent of the disease burden due to hypertension occurs in adults under 60 and is evenly distributed among men and women. ${ }^{17}$

\section{Cancer}

Until recently, any cancer diagnosis evoked the specter of a long, painful death; fortunately, research and medical sciences have made great strides in discovering the causes and finding effective treatments. At least onethird of cancer is now preventable and another third can be detected early and treated effectively. ${ }^{18,19}$ Yet achieving the full potential for prevention and treatment of cancer poses significant challenges, particularly as the world population ages in the coming decades. Assuming an annual increase in cancer incidence and mortality of 1 percent, by 2030 there could be up to 26.8 million new cases of cancer and 17.1 million cancer deaths every year, as well as 80 million people living with cancer within 5 years of diagnosis. ${ }^{20}$ 
In 2007, there were over 12 million new cancer cases, 7.6 million cancer deaths, and over 24 million cancer survivors globally. The most common cancers diagnosed globally were lung cancer (1.5 million), breast cancer (1.3 million), and colorectal cancer (1.2 million). Lung cancer (1.45 million deaths) ranked first in the mortality scale, followed by stomach cancer (800,000 deaths), and liver cancer (680,000 deaths). Among men, the most common causes of cancer mortality are lung, stomach, liver, colorectal, esophagus and prostate; among women they are breast, lung, stomach, colorectal and cervical. ${ }^{21,22}$

Incidence, prevalence, and survival rates for specific cancers reveal much about health equity within and between countries. This is less clear for poor-prognosis cancers, such as pancreatic cancer, where relatively little is known about their causes, and the mortality rates for those diagnosed approaches 100 percent worldwide. Those cancers that are highly susceptible to preventive measures, screening, and treatment tell a different story. Easily treatable if women undergo regular Pap screening, ${ }^{23}$ cervical cancer is a clear case where secondary prevention and treatment can avert hundreds of thousands of deaths of relatively young women globally. Moreover, new knowledge on the fundamental role of the HPV as a direct cause of cervical cancer has led to development of effective vaccines against this infection, which has opened the possibiltity of controlling and potentially eliminating this disease - at least in areas where girls and women have access to immunizations. ${ }^{24,25}$

\section{Diabetes Mellitus}

Diabetes mellitus is a major risk factor for heart disease, stroke, hypertension, dyslipidemia, Metabolic Syndrome, and end stage renal disease ${ }^{26} \mathrm{CVD}$ mortality among persons with diabetes is estimated at about 75-80 percent, ${ }^{27}$ with markedly worse results for men. ${ }^{28}$ Currently affecting about 285 million people worldwide, the prevalence of diabetes is projected to increase over 50 percent in the next 20 years, reaching 438 million people, or nearly 8 percent of the adult population. ${ }^{29}$ The most at-risk individuals are those suffering from dysglycaemia, or the disturbance of blood-sugar regulation. ${ }^{30}$

The main risks driving prevalence of diabetes upwards are related to poor diet, lack of physical activity, and obesity. The westernization of lifestyles and increased urbanization originating in industrialized nations has spread to LMICs, as well. Thus, as with CVD and cancer, most of the growing burden of diabetes will be borne by the developing world..$^{31,32}$ 


\section{CHRONIC DISEASE EPIDEMIOLOGY: SHARED RISK FACTORS}

Evidence shows that morbidity and mortality from chronic diseases can be greatly decreased by reducing the prevalence of the major behavioral risk factors for these conditions. Tobacco use, unhealthy diet, and lack of sustained physical activity are associated with many chronic conditions, as are specific preventable infections that lead to chronic disease. Because of the shared impact of these risk factors, a concerted effort to modify health behaviors inevitably has positive repercussions on the disease burden for CVD (heart disease and stroke), cancer, diabetes, respiratory diseases, and many other conditions. Estimations carried out by Ezzati and colleagues affirm that a concerted effort to target key risk factors for chronic diseases could have important repercussions on healthy life expectancy. ${ }^{33}$ This strategy of changing health behaviors, together with increasing awareness of chronic conditions, and promoting the timely use of disease-screening practices, should be central to any effective and comprehensive public health strategy to prevent chronic disease. ${ }^{34}$

\section{Tobacco Use}

Scientific evidence of harm caused by smoking cigarettes reached a critical turning point in the mid-1960s. ${ }^{35}$ At present, nearly 40 causes of death are known to be associated with tobacco use ${ }^{36}$ making it the most avoidable risk factor for premature death in the world. Tobacco has surpassed hypertension as the number one risk factor for loss of DALYs in developed regions, ${ }^{37}$ where the burden is evenly distributed among men and women. Globally, tobacco-related illnesses cause almost 5 million deaths a year, most of them among men in developing countries. ${ }^{38}$ Recent figures on tobacco prevalence indicate that the future disease burden linked to tobacco use will continue to rise (Figure 1).

Environmental tobacco or second-hand smoke, which is a Group 1 carcinogen, leads the list of avoidable risk factors for cancer, causing between 16 percent (in developing countries) and 30 percent (in industrialized countries) of cancers worldwide. ${ }^{39}$ Nearly all lung cancers (about 87-91 percent in men and 57-86 percent in women $)^{40}$ are attributable to tobacco use, along with most cancers of the esophagus, larynx, and oral cavity. Tobacco is also a significant risk factor for cancers of the bladder, pancreas, kidney, stomach, cervix, and nose, as well as myeloid leukaemia. ${ }^{25}$

Accumulated evidence has also established a direct causal link between tobacco use and CVD. ${ }^{41}$ Smokers are twice as likely as non-smokers to die from coronary heart disease, ${ }^{42}$ and they are at serious risk for sudden cardiac 
death due to acute coronary thrombosis and stroke. ${ }^{43,44}$ Moreover, over 50,000 deaths from ischemic heart disease are associated with secondhand smoke annually, ${ }^{45}$ making exposure to tobacco smoke a concern for the entire population, not just those who use tobacco products.

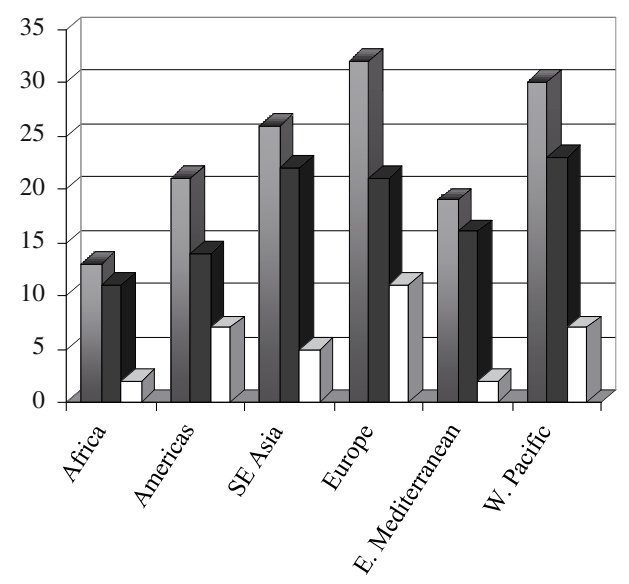

Total prevalence estimate (\%)

$\square$ Proportion of prevalence estimate attributable to men $(\%)$

$\square$ Proportion of prevalence estimate attributable to women (\%)

Fig. 1. Age-standardized estimates for smoking among adults, weighted by sex, 2006.

Source: WHO. WHO report on the global tobacco epidemic, 2009: Implementing smoke-free environments. Geneva: World Health Organization; 2009.

Tobacco use also increases the risk of acquiring or worsening diabetes ${ }^{46}$ It is associated with poorer metabolic control in persons with diabetes ${ }^{47}$ as well as an increased risk for development of micro- and macrovascular complications and mortality. ${ }^{48,49}$

\section{Diet, Physical Activity, and Obesity}

These three risk factors are separate but closely intertwined and should therefore be considered both alone and in concert. Taken as a whole, the convergence of a poor diet, an inactive lifestyle, and obesity are a lethal combination to health, increasing the risk of developing a long list of chronic conditions, including CVD, diabetes mellitus, and cancer, as well as metabolic syndrome, gallbladder disease, osteoarthritis, and others. Obesity has reached epidemic proportions in industrialized nations and is rapidly rising in developing countries ${ }^{50}$ affecting women more than men. ${ }^{17}$ 
Global dietary patterns are increasingly characterized by greater intake of high caloric sugar sweeteners, salt, animal fats, and edible oils. Meanwhile, energy expenditure is being reduced at work, at home, and during leisure activities, affecting all age groups. The inexorable trends of declining food prices, increased access to supermarkets, and large-scale urbanization are key underlying factors that drive these trends. ${ }^{51}$ Despite the acute urgency of the problem, we still have much to learn about how these risk factors contribute to chronic diseases, and how to reverse the trend..$^{52}$

\section{Considering Diet Patterns over Diet Content}

Gradually, nutritional epidemiology has moved from analyzing specific food items or micronutrients and their benefits or harms towards a more holistic view that identifies diet patterns and tendencies. Of these, the "Mediterranean diet," or "prudent diet" is the most commonly cited in a positive light. The term refers to dietary patterns found in olive-growing areas of the Mediterranean region, where there are common features in the consumption of specific foods and nutrients, such as olive oil as the main source of fat, whole grain cereals, a variety of fresh vegetables (plant foods) and fruits (as the main and usual dessert), frequent consumption of fish, moderate but consistent wine consumption with meals, and relatively low amounts of red meat. Among the common components identified in such a diet are: a high monounsaturated/saturated fat ratio and omega-3 fatty acids; ethanol intake at moderate levels; high intake of fiber, vitamins, folate, and natural antioxidants; and low intake of animal protein, all beneficial for human health. ${ }^{53,54}$

\section{Physical Activity}

Physical activity and cardiorespiratory fitness, inversely associated with CVD morbidity and mortality, are promising pathways towards reducing chronic disease risk and improving overall health. Studies have shown that sustained physical activity at moderate to vigorous levels yields multiple health benefits at all ages, including a lower risk of incident diabetes and hypertension. Moreover, moderate to vigorous exercise training can lower blood pressure in hypertensive adults ${ }^{55,56}$ and act as a protective factor for some types of cancer, independently of weight. ${ }^{57}$ As populations age, the importance of routine physical activity (e.g., walking rather than driving) will play an increasingly important role in health promotion..$^{58}$ 


\section{Obesity}

Obesity, usually a direct result of poor diet and physical inactivity, is associated with a high risk of morbidity and mortality in the general population and is responsible for up to 39 percent of the global burden of CVD, causing worsening and rapid progression of diabetes, hypertension, dyslipidemia, and other components of the metabolic syndrome. ${ }^{59}$ Excess weight also increases low-density lipoprotein cholesterol, hypertriglyceridemia, and glucose intolerance, and affects cardiac structure through direct maladaptive effects.

Obesity is also an important risk factor for several types of cancers. In Western Europe, overweight and obesity are the main causes of approximately 11 percent of colon cancer, 9 percent of breast cancer, 39 percent of endometrial cancer, 37 percent of esophageal adenocarcinomas, 25 percent of kidney cancer, and 24 percent of gallbladder cancer. ${ }^{25}$

Obesity and physical inactivity are both independent risk factors for type 2 diabetes, but obesity seems to play a more important role. The excessive free fatty acid released by adipose tissue leads to a decrease in insulin sensitivity of muscle, fat, and liver, which is followed by higher glucose levels and insulin resistance. Physical activity may increase insulin sensitivity, glucose disposal, and free fatty acid's oxidative capability. However, it has no noticeable effect on glucose regulation, insulin action, and other metabolic complications in obese individuals without additional weight loss. The positive biological interaction between obesity and physical inactivity support this combined pathophysiology ${ }^{60}$

\section{Infectious Agents}

In addition to behavioral risk factors, infectious agents have also been found to increase the risk of developing some cancers. ${ }^{61,62}$ The most well known of these is HPV, present in virtually all cervical cancer biopsies and 5.2 percent of total cancers. ${ }^{24}$ Likewise, hepatitis B (HBV) and hepatitis C (HCV) (together accounting for 4.9 percent of all cancers) are important risk factors for liver cancer and cirrhosis; and Helicobacter pylori (HP) (in 5.5 percent of all cancers) causes up to 65 percent of stomach cancers, in addition to much suffering from chronic peptic ulcers. ${ }^{63}$ AIDS is also strongly associated with many cancers, particularly Kaposi's sarcoma and Non-Hodgkin's Lymphoma, but also Hodgkin's disease, myeloma, brain cancer, testicular cancer, and others. ${ }^{64}$ 


\section{INTERVENTIONS FOR CHRONIC DISEASE PREVENTION}

A comprehensive and integrated New Public Health approach to chronic disease prevention focuses on the shared risk factors that contribute to the global burden of chronic disease morbidity, disability, and premature death. The prevention of chronic disease involves adopting effective interventions targeted at the major risk factors for chronic disease. ${ }^{65}$ Below, we rely on the growing scientific evidence base to identify the most effective interventions targeted at the individual, community, and population levels. ${ }^{68}$

Evidence is strongest for measures aimed at reducing tobacco use and increasing physical activity in Western populations, while large gaps remain in our knowledge about how to effectively change eating habits and achieve healthy weights in a population. Despite valuable studies in lower income contexts, ${ }^{66}$ the validity of many research results has not been established outside the industrialized world. In particular, many of the interventions that rely on the delivery of primary and preventive healthcare services are probably not feasible in many LMICs, where infrastructure is limited and funding is severely constrained.

Below we review the findings of available research, sharing recommendations that are strongly supported by current scientific evidence. It should be noted, however, that this field is extremely dynamic, with new research on clinical preventive care, as well as community- and populationbased interventions, emerging constantly. These circumstances - and the millions of lives that can be saved through effective public policy and public health action - demand that chronic disease prevention remain a top research priority.

Interventions are discussed under the three major strategies that effectively reduce chronic disease risk in a population: healthy public policy, community-based programs, and clinical preventive services. ${ }^{67}$

\section{Healthy Public Policy}

The first, also sometimes referred to as Health in All Policies, alludes to public policy and governmental interventions designed to change both the environment, as well as individual behavior to promote health and prevent chronic disease throughout society. The 1974 Lalonde report reopened the concept of a broad link between population health and economic, social, lifestyle, and environmental policy, in addition to genetic potential and medical care. ${ }^{68}$ Since then, evidence has mounted to support intersectoral approaches across a broad spectrum of government actions as a key to effective public health improvement. 


\section{Community-Based Programs}

The second are community interventions by local institutions delivered at the population level. These may include school-based and workplace health promotion, community education, communication, training, public awareness campaigns, social support, city redesign, and public health and healthcare delivery system reforms. ${ }^{69}$

\section{Clinical Preventive Services}

Clinical preventive services delivered by health professionals to individuals are effective in the prevention and early detection of disease. Again, it is likely that LMICs face the greatest challenge in adopting this approach without significant development of their primary care infrastructure and resources targeted for this purpose.

The old nomenclature of "primary, secondary, and tertiary" prevention has been replaced by a taxonomy that describes the discreet preventive services delivered by health workers to patients. The problem with the old taxonomy is that services often fell under more than one category. Counselling services, for example, regarding tobacco use or healthy diet can be primary, secondary, and tertiary prevention. Instead, we have adopted the nomenclature used by the U.S. Preventive Services Task Force that categorizes preventive care into four types of services: 1) behavioral counselling services, 2) screening tests for asymptomatic disease, 3) chemoprophylaxis, and 4) immunizations. ${ }^{70}$

It should also be pointed out that most of the preventive services recommended here have been found to be highly cost-effective, though not necessarily cost-saving. By cost-effective, we mean that the cost per quality-adjusted life year (QUALY) is relatively low and the reduced burden of disease is relatively high. In a recent systematic review of the effectiveness and cost-effectiveness of clinical preventive services, the following were identified as being highly cost-effective for preventing chronic disease: aspirin chemoprophylaxis, tobacco use screening and brief intervention, hypertension screening, as well as colorectal, cervical, and breast cancer screening. ${ }^{71}$ Each of these is discussed in more detail below.

\section{Reducing Tobacco Use and Exposure}

Interventions to decrease the use of tobacco and exposure to second-hand smoke in a population are effective at all three levels - public policy, community-based programs, and individual clinical preventive services. The research evidence of their effectiveness in reducing premature death 
and disease is well established. The WHO Framework Convention on Tobacco Control, a set of effective and cost efficient measures to reduce tobacco consumption and exposure, embodies this approach and provides a blueprint for the 167 countries which have ratified the treaty so far, which have chosen to address this risk factor in a comprehensive way. ${ }^{72}$

In addition, the evidence-based Clinical Practice Guideline for Treating Tobacco Use and Dependence developed by the U.S. Agency for Healthcare Research and Quality recommends specific treatments to help tobacco users quit based on a comprehensive review of the scientific literature on their efficacy and effectiveness. ${ }^{73}$

While all of the interventions detailed below have some impact when considered alone, there is a clear added value when they are implemented together, indicating that a truly comprehensive response from all levels of society is necessary in order to achieve the best results in tobacco use prevention and cessation.

\section{PUBLIC POLICY FOR REDUCING TOBACCO USE AND EXPOSURE}

Effective public policies that reduce tobacco use are reviewed below and include policies to reduce the demand for and restrict the supply of tobacco products, as well as to protect the public against harmful exposure to second-hand smoke. ${ }^{69,72}$ A 2003 review of tobacco control efforts around the globe found that tobacco use can be reduced cost-effectively in high-, middle- and low-income countries. ${ }^{74}$ Some of the most effective public policies designed to reduce consumption of tobacco products are those that decrease the demand for tobacco. These include:

Raising excise taxes on tobacco: Excise taxes are effective in reducing tobacco use in adolescents and adults, reducing tobacco consumption, and increasing tobacco cessation..$^{69,72}$

Lowering the cost of treatments: Removing all out-of-pocket costs for tobacco dependence treatments (including behavioral counselling, nicotine replacement therapy, and other smoking cessation medications) is effective in increasing their use and subsequent quit rates. ${ }^{69,72}$

Non-price policies are widely used regulatory approaches which are also effective in reducing demand for tobacco and include:

Regulating exposure to environmental tobacco smoke: Smoking bans and restrictions of tobacco use in indoor workplaces, public transportation, public indoor spaces, and other public places are effective in reducing exposure to environmental tobacco smoke. ${ }^{69,72}$ 
Regulating the contents of tobacco products: Policies that require manufacturers and importers of tobacco products to disclose information about the toxic contents and harmful emissions of tobacco products to governmental authorities and the public are effective in reducing the demand for tobacco products..$^{69,72}$

Regulating packaging and labelling: Policies that require that each pack and carton of tobacco products and any outside packaging and labelling carry health warnings on the harmful effects of tobacco use and toxic emissions of tobacco products are effective in reducing the demand for tobacco products. ${ }^{69,72}$

Banning tobacco advertising, promotion, and sponsorship: A comprehensive ban on advertising, promotion, and sponsorship of tobacco products reduces their consumption, as does a comprehensive ban on cross-border advertising, promotion, and sponsorship. ${ }^{69,72}$

Public policy is also effective in reducing the supply of tobacco products:

Prohibiting tobacco sales to minors: Prohibiting the sale of tobacco to minors combined with active enforcement of retailer sales laws is effective in reducing the accessibility of tobacco products to minors, as is prohibiting the manufacture and sale of tobacco-related sweets, snacks, toys or any other tobacco products targeted to minors..$^{69,72}$

Regulating physical access to tobacco products: Banning the sale of tobacco products in any manner that makes them directly accessible, such as on store shelves, and adopting a total ban on vending machine sales, reduces access to tobacco products. ${ }^{69,72}$

Eliminating illicit trade: The elimination of all forms of illicit trade of tobacco products is an effective component of tobacco control, reducing access to tobacco products. ${ }^{72}$

\section{COMMUNITY-BASED PROGRAMS TO REDUCE TOBACCO USE}

Education, communication, training, and public awareness to reduce tobacco rely on a variety of methods. Mass media campaigns to reduce tobacco use, particularly targeted at adolescents, are effective when implemented with excise tax increases and community-based education programs. ${ }^{69}$ Training and awareness programs on tobacco control should be targeted to health workers, community workers, social workers, media professionals, educators, decision-makers, and administrators. Communication to promote tobacco use cessation should also be targeted to institutions such as schools, healthcare facilities, workplaces, sporting, and other group environments. 
Communications to public and private agencies and non-governmental organizations increase their awareness of and participation in tobacco control programs including the development and implementation of intersectoral programs and strategies.

Worksite health promotion programs: Worksite cessation interventions (e.g., group and individual counselling, nicotine replacement therapy) are effective in helping employees quit, ${ }^{75}$ as are smoke-free regulations. Worksite incentive programs and competitions to increase cessation are also effective when combined with the above interventions. ${ }^{69}$

Healthcare delivery system changes to support quitting: Provider reminder systems (e.g., chart stickers, expanded vital signs checklists, flowcharts, electronic reminders) are effective in increasing the rates at which providers deliver advice to quit for patients who use tobacco. ${ }^{69,73}$ In addition, providing insurance coverage for or subsidizing the costs of tobacco dependence treatments is effective in increasing use of treatments and successful quitting. ${ }^{69,73}$

\section{CLINICAL PREVENTIVE SERVICES FOR TREATING TOBACCO USE AND DEPENDENCE}

The healthcare system and both primary care and specialty medical professionals have an important role to play in assisting tobacco users to quit. ${ }^{73}$ However, in LMICs, where access to and affordability of preventive care is lacking, the public policy and community-based interventions are likely to be most effective and feasible.

Clinical Practice Guidelines: Adoption and dissemination of comprehensive, evidence-based clinical practice guidelines on treating tobacco dependence to medical professionals are effective in promoting cessation of tobacco use and providing adequate treatment. Guidelines address the diagnosis and treatment of tobacco dependence and provision of counselling services and pharmacotherapy to support cessation. ${ }^{73}$

Pharmaceuticals: Pharmaceuticals for treating tobacco use and dependence that are effective and have been approved by the Food and Drug Administration in the US include nicotine replacement therapy (chewing gum, throat lozenge, inhaler, transdermal patch, and nasal spray), bupropion SR, and varenicline. Combination therapies are also effective. ${ }^{73}$

Screening: Healthcare providers should ask patients about their tobacco use at every visit and document their status in the medical record. ${ }^{73}$

Health Behavior Programs: Brief tobacco cessation counselling interventions offered to all adults, including pregnant women, are effective 
and include screening for tobacco use, three minutes or less of counselling, and/or offering pharmacotherapy. ${ }^{73}$ These programs are effective in increasing quit rates when adopted in both clinical and community settings. ${ }^{70}$ In addition, proactive telephone counselling with multiple sessions is effective in helping smokers quit and can reach large numbers of smokers. ${ }^{69,73,76}$

\section{PHYSICAL ACTIVITY}

\section{Public Policy to Increase Physical Activity}

The positive health effects of changing the built environment through land use redesign to promote physical activity are remarkable and constitute a fascinating area where disease prevention and urban planning intersect. ${ }^{77}$ Effective policies to increase physical activity in a community involve changing planning and development of the physical environment to include design elements that take into consideration the distance from residential areas to stores, workplaces, schools, and recreation areas, the continuity and connectivity of sidewalks and streets, aesthetic and safety aspects of the physical environment, and policies such as zoning regulations, building codes, builders' practices, and other governmental policies. ${ }^{69}$

Selected changes at a neighbourhood level can also bring positive results when physical activity is facilitated through changes in roadway design standards and environment. Design components include improved street lighting, infrastructure projects to increase safety of street crossings, use of traffic calming approaches (e.g., speed bumps, traffic circles), and enhancing street landscaping. ${ }^{69}$ This New Public Health approach to urban planning is of crucial importance and could have important repercussions in population health, particularly for those who cannot or do not find opportunities to follow an exercise regimen.

\section{COMMUNITY-BASED PROGRAMS FOR PHYSICAL ACTIVITY}

Highly visible, broad-based, multi-component strategies can also work to increase physical activity in a community, particularly through education, communication, training, and public awareness campaigns. ${ }^{69}$ The goal of all interventions should be to make physical activity easy and desirable, by increasing the social component of exercise and providing education on its positive health effects. A simple example of an effective way to increase the ease and desirability of physical activity is to use point-of-decision prompts 
at elevators, which inform people of the health benefits of stair-climbing. Such prompts point out an immediate opportunity to be more active. ${ }^{69}$

For children and adolescents, school health education and enhanced physical education curricula (including more time spent on moderate to vigorous exercise) can contribute to improved health awareness and physical fitness. ${ }^{69}$ Likewise, classes for children and parents aimed at reducing screen time (time in front of the TV or computer) are an effective way to improve weight-related outcomes. ${ }^{69}$

Community coalitions, including businesses and other agencies, can contribute by political advocacy, raising population awareness and helping to increase access to exercise facilities by creating walking trails, building exercise facilities, or facilitating access to existing resources ${ }^{69}$ Including a social element is also important; interventions that create and maintain supportive relationships for behavior change can include setting up a buddy system and making contracts with others to complete specified levels of physical activity, or setting up walking groups, sports teams or other groups, which provide friendship and support. ${ }^{69}$

\section{CLINICAL PREVENTIVE SERVICES TO INCREASE PHYSICAL ACTIVITY}

Adopting and disseminating existing evidence-based clinical practice guidelines for increasing physical activity are also effective. ${ }^{78}$ The following evidence-based guidelines recommend levels of physical activity for different age groups of the population:

Children and adolescents: 60 minutes (1 hour) or more of physical activity per day is recommended, including aerobic activity, muscle strengthening, and bone strengthening.

Adults and older adults (65 years and older who are generally fit and have no limiting health conditions) - 150 minutes ( 2.5 hours) a week of moderate to vigorous activity spread out during the week for at least 10 minutes at a time, including aerobic activity and muscle strengthening. Activities as simple as walking and gardening will provide a level of physical activity sufficient to achieve health benefits.

Finally, implementing behavior change programs adapted to each individual is effective in increasing physical activity and improving physical fitness among adults and children. ${ }^{69}$ 


\section{HEALTHY DIET}

\section{Public policy for a healthy diet}

Based on the successful use of public policy for tobacco control and increasing physical activity, several public policies have been proposed and implemented to restrict the supply of or access to unhealthy foods, as well as to increase availability and demand for healthy foods. Given the dynamic context in which these policies are emerging, there is an urgent need for research to evaluate their effectiveness on changes in dietary patterns and clinical outcomes.

Examples of policy to restrict access to unhealthy foods and increase access to healthy foods include: ${ }^{79}$

- Tort liability against the food industry for failing to disclose health risks, deceptive practices, and false advertising of health claims ${ }^{79}$;

- Replacement of unhealthy foods in school cafeterias with increased choices of fruits, vegetables, and nutritious alternatives ${ }^{80}$;

- Disclosure requirements for food labelling, identifying ingredients, and posting warnings ${ }^{79}$;

- Regulation of food advertising and marketing to children ${ }^{81}$;

- Taxation of high-energy, low-nutrient foods (e.g., sweetened soft drinks) ${ }^{82}$;

- Decreasing the salt content of prepared foods through regulation or prohibition combined with mass media campaigns to educate populations on the benefits of reducing salt intake ${ }^{83,84}$;

- Zoning laws that regulate the location of fast food establishments ${ }^{85}$ and expand access to fruits and vegetables (e.g., farmers markets) ${ }^{86}$; and

- Prohibiting the use of specific ingredients in the food supply (e.g., trans-fats). ${ }^{79,87}$

\section{Community-based programs for a healthy diet}

While interventions are needed to increase access to healthier foods in communities, very little research has evaluated the effectiveness of such programs. Programs that have experienced some early success include supporting community gardening to grow vegetables and fruits, introducing healthier foods and beverages to local stores, and making farmer's markets available to urban communities. ${ }^{86}$ Fortifying foods with micronutrients is a longstanding method of increasing population levels of essential micronutrients that can be difficult to obtain particularly for people on low incomes (iodine in salt; folic acid, iron, vitamin B and B12 in flour; and vitamin $\mathrm{D}$ in milk), and is also an effective and efficient way to reduce these nutritional deficiencies. ${ }^{61,88}$ 
Several intervention studies have shown the positive effect that components of the "Mediterranean diet" have on chronic disease markers such as blood pressure, lipid profiles, oxidative stress levels, insulin resistance, and body fat. ${ }^{89,90}$ Studies have shown that adherence to the Mediterranean diet reduces the risk of CVD, metabolic syndrome, and diabetes. ${ }^{91,92}$ However, further evidence is needed to formulate feasible and effective interventions, including ensuring access to these foods and increasing long-term compliance, and identification of the most effective methods for implementing programs in diverse communities. ${ }^{93,94}$

\section{Worksite programs to control overweight and obesity}

Worksite programs intended to improve diet and/or increase physical activity behaviors are effective in reducing weight among employees. Effective interventions include information and educational strategies, behavioral and social strategies, as well as policy and environmental approaches to increase access to healthful food and provide opportunities for physical activity. ${ }^{69}$

\section{Clinical preventive services for a healthy diet}

As with tobacco and physical activity, comprehensive, evidence-based guidelines on healthful diets are important in clinical preventive efforts. Research finds that exposure to certain foods is associated with either decreased or increased risks for specific chronic conditions, providing clear support for clinical interventions. ${ }^{95,96}$

Evidence on specific food items supports the recommendation for a balanced diet (such as the Mediterranean diet) rich in fruits, vegetables, legumes, whole grain cereals, nuts, fish (especially oily fish), and unsaturated fats. Valuable components include iodized salt (and other micronutrients such as iron and folic acid in flour or supplements such as vitamin D at recommended levels) and foods that contain lycopene (mostly tomatoes and tomato products; also grapefruit, watermelon, guava, and apricot), and selenium (found in roots and tubers, most notably potatoes), which are protective against prostate cancer in men.

It is also important to limit consumption of energy-dense, nutrition poor foods high in total fat, saturated fat, sugar, and salt (sodium). The intake of trans-fatty acids, free sugars, beta-carotene supplements (associated with increased risk of lung cancer), and calcium-rich foods (associated with increased risk of prostate cancer) should be reduced or elimated. 


\section{SCREENING FOR OBESITY}

Body mass index $\left(\mathrm{BMI}=\mathrm{kg} / \mathrm{m}^{2}\right)$ is a valid method for screening and identifying adults who are overweight or obese. High-intensity counselling about diet, exercise or both, together with behavioral interventions are effective in producing modest, sustained weight loss (typically 3-5 kg for 1 year or more) in adults who are obese (defined as BMI $\geq 30 \mathrm{~kg} / \mathrm{m}^{2}$ ). Modest weight loss is effective in improving intermediate health outcomes, such as glucose metabolism, lipid levels, and blood pressure, but does not reduce mortality. ${ }^{70}$

Among adult patients with hyperlipidemia and other risk factors for dietrelated chronic disease, intensive behavioral dietary counselling interventions are effective in changing average daily intake of core components of a healthy diet (including reduced saturated fat, and increased fibre, fruit, and vegetables). Effective interventions combine nutrition education with behavioral counselling provided by a nutritionist, dietician, or specially trained primary care clinician (e.g., physician, nurse, or nurse practitioner).$^{70}$

Another area of interest and growing research is micronutrient deficiencies. It is clear that an inadequate intake of specific micronutrients is associated with an increased risk of both CVD and cancer. The approaches taken to increase micronutrients in a population include increasing the intake of micronutrient-rich foods, food fortification, and the use of supplements. While a strong association between consumption of high levels of vitamin D, vitamin C, folic acid, and beta-carotene and a lower risk of CVD, stroke, and cancer has been observed in cohort studies, a similar relationship has not been demonstrated in randomized trials of micronutrient supplements. ${ }^{97,98}$ It is not clear if the differences in clinical outcomes are due to the complex nature of micronutrients in whole foods (e.g., fruits and vegetables) versus the administration of a single micronutrient as a supplement or in fortified food. The research to date supports interventions that promote the consumption of whole foods or a dietary pattern (such as the Mediterranean diet) as the most effective approach for increasing micronutrient consumption, but fortification of basic foods with key micronutrients is also part of current best practices in public health.

\section{RECOMMENDED CLINICAL PREVENTIVE SERVICES FOR CHRONIC DISEASE PREVENTION}

While the above review summarizes the policies and strategies that are most effective in reducing the three major risk factors for chronic disease 
- tobacco use, physical inactivity and unhealthy diet - there are other intermediary endpoints such as high blood pressure and cholesterol, as well as additional screening tests, pharmaceuticals, and immunizations that are effective in the prevention and early detection of chronic disease and its precursors.

We recognize that adoption of many of these recommendations may simply not be feasible in many LMICs due to limited resources and inadequate primary care and public health systems., ${ }^{299}$ Low-income populations generally have the least access to preventive care. Thus, a great deal of research is needed to find cost-effective ways to deliver clinical preventive services in LMICs. Dietary improvement to low-income populations, even in the industrialized societies with large gaps between upper and lower income groups, is an important element of current challenges to public health, including ready access to healthful foods such as fruit and vegetables of good quality and at reasonable prices.

\section{Screening}

Screening involves the early detection of disease when the individual is asymptomatic. Screening is only recommended when there is evidence that early detection and treatment effectively reduce the risk of premature death and morbidity, and it is most effective when structural and economic barriers are reduced, when patients are reminded to come in for a screening procedure, and when they have access to education. ${ }^{69,70,100}$ Screening for tobacco use, physical activity and obesity were addressed in the previous sections of the paper.

Cancer screening: There is strong evidence to recommend cancer screening for breast, cervical, and colorectal cancer. ${ }^{70,100}$ However, the frequency and age range of recommendations vary by country and organization (Table 1), indicating that additional research is needed to determine the most cost-effective approach for improving health outcomes. Screening for other cancers, such as prostate cancer, has not proven to increase survival rates or quality of life for patients thus far. ${ }^{70}$ 
Table 1

Cancer Screening Recommendations

by the United States and European Union

\begin{tabular}{|c|c|c|c|}
\hline Organization & Cervical Cancer & Breast Cancer & Colorectal cancer \\
\hline $\begin{array}{l}\text { U.S. Preventive } \\
\text { Services Task }\end{array}$ & $\begin{array}{l}\text { Begin Pap } \\
\text { screening within }\end{array}$ & $\begin{array}{l}\text { Screening } \\
\text { mammography every }\end{array}$ & $\begin{array}{l}\text { Screening for colorectal } \\
\text { cancer in adults ages } 50\end{array}$ \\
\hline Force $^{70}$ & $\begin{array}{l}3 \text { years of onset of } \\
\text { sexual activity or } \\
\text { age } 21 \text { (whichever } \\
\text { comes first) and } \\
\text { screen at least every } \\
3 \text { years to age } 65\end{array}$ & $\begin{array}{l}2 \text { years for women } \\
\text { aged } 50 \text { and older }\end{array}$ & $\begin{array}{l}\text { to } 74 \text { years using one of } \\
\text { three regimen: } 1 \text { ) annual } \\
\text { fecal occult blood test } \\
\text { (FOBT), 2) } \\
\text { sigmoidoscopy every } \\
5 \text { years combined with } \\
\text { FOB every } 3 \text { years, or } 3 \text { ) } \\
\text { screening colonoscopy } \\
\text { at intervals of } 10 \text { years }\end{array}$ \\
\hline $\begin{array}{l}\text { European Code } \\
\text { Against } \\
\text { Cancer }^{100}\end{array}$ & $\begin{array}{l}\text { Pap screening every } \\
3-5 \text { years for } \\
\text { women ages } 25-60\end{array}$ & $\begin{array}{l}\text { Mammography } \\
\text { screening for women } \\
50-69 \text { (interval not } \\
\text { specified) }\end{array}$ & $\begin{array}{l}\text { FOBT screening every } \\
\text { two years for adults over } \\
50\end{array}$ \\
\hline
\end{tabular}

CVD Screening: Below we identify the individual screening tests for conditions that are precursors in developing CVD. However, it should be noted that the extent of the treatment for each of these risk factors should be adjusted to the absolute cardiovascular risk of each patient, as measured by the Framingham or SCORE equations, or country specific equations (e.g., QRISK in England). ${ }^{101}$ There is strong evidence to support screening for:

Elevated Blood Pressure in adults aged 18 years and older. Adults with blood pressure below 120/80 $\mathrm{mm} \mathrm{Hg}$ should be screened every two years, and those with systolic blood pressure of $120-139 \mathrm{~mm} \mathrm{Hg}$ or diastolic blood pressure of 80 to $90 \mathrm{~mm} \mathrm{Hg}$, every year. ${ }^{70}$ Management and family education are for lifelong control of blood pressure by non-pharmaceutical means (e.g., smoking cessation, exercise) and use of low cost diuretics and beta blokers.

Lipid disorders in men aged 35 and older and men aged 20-35 if they are at increased risk for CVD; and in women aged 20 and older if they are at increased risk for CVD. The indicators for which there is strong evidence showing the value of screening include total serum cholesterol, low-density lipoprotein cholesterol (LDL-C), triglycerides (TG), or low values of highdensity lipoprotein cholesterol (HDL-C) on non-fasting or fasting blood 
samples ${ }^{70}$ Here too, management is a lifelong process with patient and family education as to self care and medical management.

Type 2 Diabetes Mellitus Screening in asymptomatic adults with sustained blood pressure (either treated or untreated) greater than $135 / 80 \mathrm{~mm} \mathrm{Hg}$ is recommended. ${ }^{70}$ Managing diabetes and preventing diabetes-related complications requires strict control of blood-glucose levels through diet, exercise, insulin replacement for type 1 diabetes, and insulin stimulation by medication for type 2 diabetes. This is best delivered with a multidisciplinary team approach and well organized follow-up.

\section{CHEMOPROPHYLAXIS}

The pharmaceutical therapies that are effective in preventing heart disease, stroke, and cancer in asymptomatic patients are reviewed below.

Blood Pressure Medication: For persons with high blood pressure (over 140/90 $\mathrm{mm} \mathrm{Hg}$ ), the following drugs are effective in lowering blood pressure: in the US, a thiazide-type diuretic is recommended as the first course of treatment, and if needed, followed by an angiotensin converting enzyme inhibitor (ACE-I), an angiotensin receptor blocker (ARB), a beta blocker (BB), a calcium channel blocker (CBC), or a combination of the above. ${ }^{102}$ Under European guidelines, any of these five types of antihypertensives are recommended as first line therapies. ${ }^{103}$

Hyperlipidemia Medication: For persons with elevated blood cholesterol and elevated low-density lipoproteins (LDL $>130 \mathrm{mg} / \mathrm{dL}$ ), the following drugs are effective in lowering LDL: statins, bile acid sequestrants, or nicotinic acid. ${ }^{104}$

Aspirin Therapy: The use of daily aspirin therapy for men aged 45-79 and for women aged 55-79 is recommended when the potential benefit due to a reduction in myocardial infarction outweighs the potential harm due to increased gastrointestinal bleeding. ${ }^{70}$ This is most certainly the case for those with elevated risk factors and previous cardiovascular disease findings or events.

Chemoprevention of Breast Cancer: The U.S. Preventive Services Task Force (USPSTF) recommends against routine use of tamoxifen or raloxifene for the primary prevention of breast cancer in women at low or average risk. ${ }^{70}$ However, there is evidence that tamoxifen can reduce the risk for invasive estrogen-receptor-positive breast cancer in women at high risk and that the likelihood of benefit increases as the risk for breast cancer increases. There is less evidence for the benefit of raloxifene. It is recommended that clinicians discuss chemoprevention with women at high risk for breast cancer and at low risk for adverse effects of chemoprevention. 


\section{Immunizations and Control of Infectious Agents}

Increasingly infectious agents in the form of bacteria and viruses are associated with the development of chronic disease. Below we review the evidence where an infectious agent has been identified and an immunization effective in preventing the chronic condition is available, or early medical management of the infection to prevent the development of the chronic condition has been developed.

Human papillomavirus: There is strong evidence to support vaccination of girls against HPV, which causes cervical cancer. The initial dose of the HPV vaccine should be administered to girls at age 11 or 12 , followed by a second dose after two months and a third four months later. The HPV vaccine series should also be administered to females 13 to 26 years of age, if they have not been previously vaccinated. ${ }^{105}$ Pap smear screening of women should continue to be a fundamental part of preventive healthcare and supported by health insurance agencies and health education programs including outreach to low compliance risk groups.

Hepatitis B: To prevent chronic liver disease, it is recommended that all children be vaccinated against hepatitis B, the key determinant of chronic hepatitis, cirrhosis, and liver cancer. Children ages 7 and older should receive the hepatitis $\mathrm{B}$ and possibly hepatitis A vaccines. A three-dose series is recommended for children who have not previously been vaccinated. A two-dose series, separated by at least 4 months, of the adult formulation Recombivax HB (Reg), is recommended for children ages 11 to $15 .{ }^{106}$

Helicobacter pylori: Finally, while there is presently no vaccine to prevent the contraction of Helicobacter pylori (HP), effective drug therapies that eliminate this infection in individuals are available. Timely treatment can prevent the development of chronic ulcers, gastric cancer, and a number of other pathologies associated with this virus.

\section{GLOBAL RESPONSE TO CHRONIC DISEASE}

Progress in chronic disease prevention is uneven. Industrialized nations have achieved admirable improvements in overall health indicators (often as a result of advocacy groups and strong governmental action involving the community and professional support), although more attention should be paid to extending those results throughout the entire population. In contrast, developing countries with rapidly growing economies often have to juggle basic public health issues (e.g., ensuring access to potable water), 
while also adapting their health systems to care for their growing middle class, whose health profiles are being quickly transformed.

International agencies such as WHO and international NGOs are contributing to maintaining or expanding the focus on key chronic diseases globally, most recently through the Non-Communicable Diseases (NCD) Action Plan, ${ }^{107}$ as well as Regional Plans. These are a further reflection of the New Public Health approach, as multi-level and intersectoral actions are adapted to the national and regional context with an emphasis on surveillance and research. The National Heart, Lung, and Blood Institute (NHLBI) in the US has also made promising advances, establishing a consortium of Centers of Excellence in chronic disease management throughout LMICs. This work is being pursued in conjunction with local academic partners and authorities to foster research, training, and health policy at local, regional, national, and international levels. ${ }^{108}$

In LMICs, these challenges are hindered by lack of funding, shortages in qualified professionals and modern equipment, and problems with management and stewardship. All of these setbacks are framed within difficult political and social contexts.

\section{PERSISTENT CHALLENGES IN CHRONIC DISEASE CONTROL IN THE INDUSTRIALIZED WORLD}

In the past decades, research from developed countries has revealed many of the contributing and direct causes of the most deadly chronic diseases, as well as established evidence-based interventions that can have a very marked effect on these conditions and their associated mortality. We can point to important successes in CVD and cancer mortality, as well as in tackling tobacco use and physical inactivity.

However, despite existing knowledge and skills with effective preventive measures, they are not adopted rapidly or even widely. They are not implemented homogeneously, even in countries that have made health and social equity a political priority. For example, many European countries have used strong welfare policies to narrow the income gap between the wealthiest and poorest citizens and to extend access to healthcare across society, yet lung cancer incidence and mortality is still closely related to socioeconomic status. ${ }^{109}$

Thus, the most advanced health systems in the world still face an enormous challenge in living up to the noble goal of "universal" healthcare. Some of the blame can be attributed to shortcomings in health systems, such as system inefficiency or qualified healthcare workforce shortages. 
However, research is accumulating on other factors that may contribute to health inequalities as well, including poor health literacy, ${ }^{110}$ geographic factors (i.e., rural/urban inequalities or socioeconomic regional differences), and other key social determinants of health. ${ }^{111}$

These newly explored complexities have contributed to the development of a New Public Health approach to address persistent challenges comprehensively in population health at the clinical, community, and societal levels. Governmental leadership with strong social advocacy group support is vital to the implementation of a New Public Health approach.

\section{CHRONIC DISEASE CONTROL IN DEVELOPING COUNTRIES}

Unlike in Western countries, where wealthier and more highly educated people use tobacco less, eat healthier diets and lead more active lifestyles, the opposite appears to be true in emerging economies. As the benefits of economic growth reach a population, consumption and health behaviors change quickly, with a tendency towards the adoption of unhealthy habits. Increased access to tobacco and unhealthful foods accompany societal shifts such as rapid urbanization, encouraging "modern" lifestyles, and technological progress leading to decreased physical activity have contributed to the spread of unhealthy behaviors. In rapidly developing countries such as India and China, this is especially apparent; as the economy grows, incidence of chronic disease increases as well. ${ }^{31}$

While public health activities focusing on chronic diseases have proven to be cost-effective, infectious diseases (in Africa, particularly HIV/AIDS) continue to dominate the attention of international donors and national health systems, overshadowing more silent killers such as CVD and cancer. Significantly, the portion of the WHO 2006-07 budget devoted to noncommunicable diseases accounted for just 12 percent of the total; 86 percent of WHO funds in the Western Pacific region went towards combating infectious diseases, despite the fact that these pathologies are only responsible for 14 percent of the mortality burden. ${ }^{112}$ Notable advances have been made in many regions, most especially in tobacco control, but few developing countries have made heart disease, cancer or diabetes a priority.

\section{CONCLUSIONS AND RECOMMENDATIONS}

Given the health burden that chronic disease represents in both developed and developing countries, as well as the social and economic burden 
resulting from increased premature morbidity and mortality and rising healthcare costs, it is imperative that societies work together at all levels to address this issue. This begins at the policy level; evidence-based health policy should be an underlying thread in urban planning, education, agricultural policy, and health systems development, along with health targets to focus and proritize needed interventions at national, regional and local levels. Population-based preventive strategies are remarkably costeffective because increasing population health is also a way to ensure continuing capacity to produce wealth. ${ }^{113}$ This message should be highlighted in prevention advocacy at both a national and international level, particularly in emerging countries. Indeed, chronic conditions merit high priority in any sensible "Global New Public Health" agenda (defined as the collective action we take worldwide for improving health and health equity). ${ }^{1}$

Numerous health organizations, universities, research groups, NGOs, donor groups, and development agencies, operating at national and international levels, play an important role in reducing chronic disease. Yet, too often these missions are hampered by poor coordination with the national health system and other actors, leading to overlap and gaps in research and population services. This is true not only in lower-income settings, but also in wealthier societies. For example, the EUROCAN+PLUS research project found that fragmented European cancer research "severely limits the total intellectual concentration on the wide cancer problem." 114 National leadership is required to place health concerns high on national agendas. International organizations should help to promote national capacity building to meet such objectives.

In contrast, the Sector Wide Approach (SWAp) has been gaining favor worldwide. This strategy transfers the ownership of all health projects to the national health authorities to strengthen national autonomy. At the same time, different foreign and national organizations across the health sector forge a common and united mission through workshops and close networking. ${ }^{115}$ This approach makes sense on many levels; however, because each disease, country, and mission is different, release of evidencebased recommendations can be difficult. Future research must address the range of experiences that SWAp will produce.

Communities also play an important role, and encouraging precedents exist that pave the way for further local action. For example, individual communities began instituting smoking bans in public places throughout the second part of the $20^{\text {th }}$ century, and today these bans help protect the air quality and save lives in dozens of countries throughout the world. Additionally, community health networks established throughout rural 
Kyrgyzstan to tackle specific health problems at a community level produced improved health results. ${ }^{116}$

Finally, professionals and professional organizations throughout the health system must do their part to tackle population risk factors decisively and proactively according to evidence-based practice and clinical guidelines. This includes extending and advancing training in the field of chronic disease prevention, as well as making this a top research priority. As communities and national policy makers strive to improve population health outcomes, public health professionals and advocacy groups must learn to act as committed partners, guiding program development, advising the public, and working to validate or discard initiatives based on the outcomes observed. Ultimately, the New Public Health requires wide recognition as both an individual and public concern; more than a goal, it must become a collective value, sustaining our society's quest for a better life for all human beings. ${ }^{17}$

Acknowledgements: The authors would like to thank Ted Tulchinsky for his encouragement and support throughout the drafting process. We would also like to acknowledge the valuable insights of Isabelle Soerjomataram, Fernando Rodríguez Artalejo and Rafael Carmena, as well as the editorial support of Meggan Harris.

Conflicts of interest: None declared.

\section{REFERENCES}

1. Beaglehole R, Ebrahim S, Reddy S, Voûte J, Leeder S, on behalf of the Chronic Disease Action Group. Prevention of chronic diseases: a call to action. Lancet. 2007;370:2152-7.

2. Nugent R. Chronic diseases in developing countries. Health and economic burdens. Ann NY Acad Sci. 2008;1136:70-9.

3. Lopez AL, Mathers CD, Ezzati M, Jamison DT, Murray CJ. Global and regional burden of disease and risk factors, 2001: systematic analysis of population health data. Lancet. 2006;367:1747-57.

4. Strong K, Mathers C, Leeder S, Beaglehole R. Preventing chronic diseases: how many lives can we save? Lancet. 2005;366:1578-82.

5. Centers for Disease Control. Achievements in public health, 1900-1999. Decline in deaths from heart disease and stroke, 1900-1999. MMWR Morb Mortal Wkly Rep.1999;48:649-56.

6. Mackay J, Mensah G. The atlas of heart disease and stroke. World Health Organization, Geneva: World Health Organization; 2004.

7. Rodriguez-Artalejo F, Guallar-Castillón P, Villar Alvarez F, Banegas JR. Critical review and proposals for improvement of the health information systems on cardiovascular diseases in Spain. Med Clin (Barc). 2008;131:30211. [article in Spanish]. 
8. World Health Organization. Cardiovascular diseases (CVDs) fact sheet 317. [online]. Available from URL: http://www.who.int/mediacentre/factsheets/fs317/ en/index.html (Updated September, 2009 and accessed 30 October, 2009).

9. Allender S, Scarborough P, Peto V, Rayner M, Leal L, Luengo-Fernandez R, Gray A. European cardiovascular disease statistics 2008. Brussels: European Heart Network: 2008. Available form: URL: http://www.ehnheart.org/content/ SectionIntro.asp?level0=1457\&docid=4345 (Accessed 1 November, 2009).

10. Appelros P, Stegmayr B, Terént A. Sex differences in stroke epidemiology: a systematic review. Stroke. 2009;40:1082-90.

11. Turk WM, Tuite PK, Burke LE. Cardiac health: primary prevention of heart disease in women. Nurs Clin N Am. 2009;44:315-25.

12. Kark M, Rasmussen F. High systolic blood pressure increases the risk of obtaining a disability pension because of cardiovascular disease: a cohort study of 903174 Swedish men. Eur J Cardiovasc Prev Rehabil. 2009;16:597602.

13. Franco OH, Peeters A, Bonneux L, de Laet C. Blood pressure in adulthood and life expectancy with cardiovascular disease in men and women. Hypertension. 2005;46:280-6.

14. Kearney PM, Whelton M, Reynolds K, Muntner P, Whelton PK, He J. Global burden of hypertension: analysis of worldwide data. Lancet. 2005;365:21723.

15. Chobanian AV. The hypertension paradox - more uncontrolled disease despite improved therapy. N Engl J Med. 2009;361:878-87.

16. Tesfaye F, Byass P, Wall S. Population based prevalence of high blood pressure among adults in Addis Ababa: uncovering a silent epidemic. BMC Cardiovasc Disord. 2009;9:39.

17. Rodgers A, Ezzati M, Vander Hoorn S, Lopez AD, Lin RB, Murray CJ; Comparative Risk Assessment Collaborating Group. Distribution of major health risks: findings from the Global Burden of Disease study. PLoS Med. 2004 Oct;1(1):e27. [Epub 2004 Oct 19].

18. Danaei G, Vander Hoorn S, Lopez AD, Murray CJ, Ezzati M; Comparative risk assessment collaborating group (Cancers). Causes of cancer in the world: comparative risk assessment of nine behavioral and environmental risk factors. Lancet. 2005;366:1784-93.

19. Soerjomataram I, de Vries E, Pukkala E, Coebergh JW. Excess of cancers in Europe: a study of eleven major cancers amenable to lifestyle change. Int J Cancer. 2007;120:1336-43.

20. Ferlay J, Bray F, Pisani P, Parkin DM. GLOBOCAN 2002; Cancer incidence, mortality and prevalence worldwide IARC CancerBase No. 5, version 2.0 Lyon (France): IARC Press; 2004.

21. Gracia M, Jemal A, Ward EM, Center MM, Hao Y, Siegel RL, et al. Global cancer facts \& figures 2007. Atlanta, (GA): American Cancer Society; 2007. Available from URL: http://www.cancer.org/downloads/STT/Global_Cancer_ Facts_and_Figures_2007_rev.pdf (Accessed 31 March, 2010). 
22. World Health Organization. Factsheet No. 297: Cancer. Available from URL: http://www.who.int/mediacentre/factsheets/fs297/en/ (Posted February, 2009, Accessed 31 March, 2010).

23. Hakama M, Coleman MP, Alexe DM, Auvinen A. Cancer screening: evidence and practice in Europe 2008. Eur J Cancer. 2008;44:1404-13.

24. Harper DM, Franco EL, Wheeler CM, Moscicki AB, Romanowski B, RoteliMartins CM, et al. Sustained efficacy up to 4.5 years of a bivalent L1 viruslike particle vaccine against human papillomavirus types 16 and 18: follow-up from a randomised control trial. Lancet. 2006;367:1247-55.

25. Castellsagué X, Díaz M, de Sanjosé S, Muñoz N, Herrero R, Franceschi S, et al. Worldwide human papillomavirus etiology of cervical adenocarcinoma and its cofactors: implications for screening and prevention. J Natl Cancer Inst. 2006;98:303-15.

26. Martinez-Hervas S, Romero P, Hevilla EB, Real JT, Priego A, Martin-Moreno JM, et al. Classical cardiovascular risk factors according to fasting plasma glucose levels. Eur J Intern Med. 2008;19:209-13.

27. Tuomilehto J, Rastenyte D, Qiao Q, Jakovljevic D. Epidemiology of macrovascular disease and hypertension in diabetes mellitus. In: De Fronso RA, Ferrannini E, Keen H, Zimmet P, editors. International Textbook of Diabetes Mellitus, 3rd ed. Milan: John Wiley \& Sons;2004. p 1345-70.

28. Australian Institute of Health and Welfare: Diabetes: Australian facts 2008. Diabetes series no. 8. Cat. No. CVD 40. Canberra: Australian Institute of Health and Welfare; 2008.

29. Unwin N, Whiting D, Gan D, Jacqmain O, Ghyoot G. Eds. IDF Diabetes Atlas, $4^{\text {th }}$ Ed. International Diabetes Federation, 2009. Available from http://www. diabetesatlas.org/ (Accessed 31 March, 2010).

30. Zimmet P. Preventing diabetic complications: a primary care perspective. Diabetes Res Clin Pract. 2009;84:107-16.

31. Lieberman LS. Dietary, evolutionary, and modernizing influences on the prevalence of type 2 diabetes. Annu Rev Nutr. 2003;23:345-77.

32. Stuckler D. Population causes and consequences of leading chronic diseases: a comparative analysis of prevailing explanations. Milbank Q. 2008;86:273326.

33. Ezzati M, Hoorn SV, Rodgers A, Lopez AD, Mathers CD, Murray CJ; Comparative Risk Assessment Collaborating Group. Estimates of global and regional potential health gains from reducing multiple major risk factors. Lancet. 2003;362:271-80. Erratum in: Lancet. 2005;365:28.

34. Ahluwalia IB, Mack KA, Murphy W, Mokdad AH, Bales VS. State-specific prevalence of selected chronic disease-related characteristics - behavioral risk factor surveillance system, 2001. MMWR Morb Mortal Wkly Rep. 2003;52(SS08);1-80.

35. Report of the Advisory Committee to the Surgeon General of the Public Health Service. Smoking and health. Public Health Service Publication. No. 1103. Washington (DC): U.S. Government Printing Office; 1964. 
36. Corrêa PC, Barreto SM, Passos VM. Smoking-attributable mortality and years of potential life lost in 16 Brazilian capitals, 2003: a prevalence-based study. BMC Public Health. 2009;9:206.

37. Ezzati M, Lopez AD, Rodgers A, Vander Hoorn S, Murray CJ; Comparative Risk Assessment Collaborating Group. Selected major risk factors and global and regional burden of disease. Lancet. 2002;360:1347-60.

38. Ezzati M, Lopez AD. Regional, disease specific patterns of smoking-attributable mortality in 2000. Tob Control. 2004; 13:388-95.

39. International Agency for Research on Cancer. Tobacco smoke and involuntary smoking. IARC Monogr Evaluat Carcinog Risks Hum. Vol. 83. Lyon (France): IARC; 2004; 83:1-1438.

40. Dreyer L, Winther JF, Pukkala E, Andersen A. Avoidable cancers in the Nordic countries. Tobacco smoking. APMIS Suppl. 1997;76:9-47.

41. Glantz SA, Parmley WW. Passive smoking and heart disease: mechanisms and risk. JAMA. 1995; 273:1047-1053.

42. Ockene IS, Miller NH., for the American Heart Association Task Force on Risk Reduction. Cigarette smoking, cardiovascular disease, and stroke: a statement for healthcare professionals. Circulation. 1997;96:3243-7.

43. Bonita R. Epidemiology of stroke. Lancet. 1992;339:342-4.

44. Burke AP, Farb A, Malcom GT, Liang YH, Smialek J, Virmani R. Coronary risk factors and plaque morphology in men with coronary disease who died suddenly. N Engl J Med. 1997;336:1276-82.

45. Wells AJ. Passive smoking as a cause of heart disease. J Am Coll Cardiol. 1994;24:546-54.

46. Will JC, Galuska DA, Ford ES, Mokdad A, Calle EF. Cigarette smoking and diabetes mellitus: Evidence of a positive association from a large prospective cohort study. Int J Epidemiol. 2001;30:540-6.

47. Bott U, Jörgens V, Grüsser M, Bender R, Mühlauser I, Berger M. Predictors of glycaemic control in type 1 diabetic patients after participation in an intensified treatment and teaching program. Diabet Med. 1994;11:362-71.

48. Chase HP, Garg SK, Marshall G, Berg CL, Harris S, Jackson WE. Cigarette smoking increases the risk of albuminuria among subjects with type I diabetes. JAMA. 1991;265:614-7.

49. Morrish NJ, Stevens LK, Fuller JH, Jarrett RJ, Keen H. Risk factors for macrovascular disease in diabetes mellitus: the London follow-up to the WHO Multinational Study of Vascular Disease in Diabetics. Diabetologia. 1991;34:590-4.

50. World Health Organization. Overweight and obesity (BMI). Health topic page. [Online]. Available from URL: https://apps.who.int/infobase/report.aspx?rid =112\&ind=BMI\&goButton=Go (Accessed 27 October, 2009).

51. Popkin BM. Global changes in diet and activity patterns as drivers of the nutrition transition. Nestle Nutr Workshop Ser Pediatr Program. 2009;63:110, 10-4,259-68.

52. Macfarlane DJ, Thomas N. Exercise and diet in weight management: updating what works. Br J Sports Med. 2009; Oct 20. [Epub ahead of print]. 
53. Martínez-González MA, Fernández-Jarne E, Serrano-Martínez M, Marti A, Martinez JA, Martín-Moreno JM. Mediterranean diet and reduction in the risk of a first acute myocardial infarction: an operational healthy dietary score. Eur J Nutr. 2002;41:153-60.

54. Guallar E, Aro A, Jiménez FJ, Martín-Moreno JM, Salminen I, van’t Veer P, et al. Omega-3 fatty acids in adipose tissue and risk of myocardial infarction: the EURAMIC study. Arterioscler Thromb Vasc Biol 1999;19:1111-8.

55. Sui X, LaMonte MJ, Blair SN. Cardiorespiratory fitness and risk of nonfatal cardiovascular disease in women and men with hypertension. Am J Hypertens. 2007;20:608-15.

56. Sieverdes JC, Sui X, Lee DC, Church TS, McClain A, Hand GA, et al. Physical activity, cardiorespiratory fitness, and the incidence of type 2 diabetes in a prospective study of men. Br J Sports Med. 2009; July 26; [Epub ahead of print].

57. Melzer K, Kayser B, Pichard C. Physical activity: the health benefits outweigh the risks. Curr Opin Clin Nutr Metab Care. 2004;7:641-7.

58. Woodcock J, Edwards P, Tonne C, Armstrong BG, Ashiru O, Banister D, et al. Public health benefits of strategies to reduce greenhouse-gas emissions: urban land transport. Lancet. 2009;374:1930-43.

59. Yusuf S, Hawken S, Ounpuu S, Dans T, Avezum A, Lanas F et al. Effect of potentially modifiable risk factors associated with myocardial infarction in 52 countries (the INTERHEART study): case-control study. Lancet. 2004;364:937-52.

60. Qin L, Knol MJ, Corpeleijn E, Stolk RP. Does physical activity modify the risk of obesity for type 2 diabetes? A review of epidemiological data. Eur J Epidemiol. 2009;25:5-12.

61. Tulchinsky TH. Micronutrient deficiency conditions: global health issues. Public Health Reviews 2010;32:243-255.

62. Schlipköter U, Flahault A. Communicable diseases: achievements and challenges for public health, Public Health Reviews 2010;32:90-119.

63. Parkin DM. The global health burden of infection-associated cancers in the year 2002. Int J Cancer. 2006;118:3030-44.

64. Goedert J, Coté T, Virgo P, Scoppa S, Kingma D, Gail M, et al., AIDS-Cancer Match Study Group. Spectrum of AIDS-associated malignant disorders. Lancet. 1998;351:1833-39.

65. World Health Organization Europe, Regional Committee for Europe. Gaining health: The European strategy for the prevention and control of noncommunicable diseases. EUR/RC56/Conf.Doc./3. 30 June 2006. Fifty-sixth session. Copenhagen, 11-14 September 2006.

66. Franco M, Orduñez P, Caballero B, Tapia Granados JA, Lazo M, Bernal JL, et al..Impact of energy intake, physical activity, and population-wide weight loss on cardiovascular disease and diabetes mortality in Cuba, 1980-2005. Am J Epidemiol. 2007;166:1374-80.

67. Schauffler HH, Faer M, Faulkner L, Shore K. Health promotion and disease prevention in health care reform. Am J Prev Med. 1994;10(5 Suppl)1-31. 
68. Lalonde M. A new perspective on the health of Canadians. A working document. Ottawa: Government of Canada; 1974. Available from http://www.hc-sc.gc. ca/hcs-sss/alt_formats/hpb-dgps/pdf/pubs/1974-lalonde/lalonde-eng.pdf (Accessed 31 March, 2010).

69. US Department of Health and Human Services. Centers for Disease Control and Prevention. Guide to Community Preventive Services. (Updated 10 February, 2009).

70. U.S. Department of Health and Human Services, Agency for Health Care Research and Quality, U.S. Preventive Services Task Force, Guide to clinical preventive services. 2009. (Updated 18 January, 2010).

71. Maciosek MV, Coffield AB, Edwards NM, Flottemesch TJ, Goodman MJ, Solberg LI. Priorities among effective clinical preventive services: results of a systematic review and analysis. Am J Prev Med. 2006:31:52-61.

72. World Health Organization. WHO Framework Convention on Tobacco Control. Geneva: WHO; 2003.

73. Fiore MC, Jaén CR, Baker TB, et al. Treating tobacco use and dependence: 2008 update. Clinical Practice Guideline. Rockville, MD: U.S. Department of Health and Human Services. Public Health Service; 2008.

74. de Beber J, Waverly Brigden L. Tobacco control policy: strategies, succeses and setbacks. Washington, DC: World Bank and Research for International Tobacco Control; 2003.

75. Cahill K, Moher M, Lancaster T. Workplace interventions for smoking cessation. Cochrane Database of Systematic Reviews. 2008; Issue 4.Art. No.: CD003440.

76. Stead LF, Perera R, Lancaster T. Telephone counseling for smoking cessation. Cochrane Database of Systematic Reviews. 2006; Issue 3. Art No.:CD002850.

77. Perdue WC, Stone LA, Goslin LO. The built environment and its relationship to the public's health: the legal framework. Am J Public Health. 2003;93:139094.

78. U.S. Department of Health and Human Services. Centers for Disease Control and Prevention. Physical activity for everyone: guidelines. November 5, 2008.

79. Gostin LO. Law as a tool to facilitate healthier lifestyles and prevent obesity. JAMA. 2007;297:87-90.

80. U.S. GAO. School lunch program: efforts needed to improve nutrition and encourage healthy eating. GAO-03-506. Washington, DC. U.S. Government Accounting Office; 2003.

81. Institute of Medicine. Food marketing to children and youth: threat or opportunity? Washington, D.C.: National Academies Press; 2006.

82. Jacobson MF, Brownell KD. Small taxes on soft drinks and snack foods to promote health. Am J Public Health. 2000;90:854-7.

83. Bibbins-Domingo K, Chertow GM, Coxson PG, Moran A, Lightwood JM, Pletcher MJ, et al. Projected effect of dietary salt reductions on future cardiovascular disease. New Engl J Med. 2010 Jan 20. [Epub ahead of print]. 
84. Asaria P, Chisholm D, Mathers C, Ezzati M, Beaglehole R. Chronic disease prevention: health effects and financial costs of strategies to reduce salt intake and control tobacco use. Lancet. 2007;370:2044-53.

85. Mair JS, Pierce MW, Teret SP. The use of zoning to restrict fast food outlets: a potencial strategy to combat obesity. The Center for the Law and Public Health. October 2005.

86. Health policy priorities..Washington, DC: Partnership for Prevention; 2005. Available from URL: http://www.prevent.org/images/stories/health_policy. pdf (Accessed 31 March, 2010).

87. PAHO/WHO Task Force. Trans fats free Americas: conclusions and recommendations. April 26-27 2007.

88. World Health Organization, the World Food Program and the United Nations Childrens Fund. Joint statement: Preventing and controlling micronutrient deficiencias in populations affected by an emergency. Geneva: World Health Organization; 2007.

89. Tyrovolas S, Panagiotakos DB. The role of Mediterranean type of diet on the development of cancer and cardiovascular disease, in the elderly: A systematic review. Maturitas. 2010;65:122-30.

90. Martinez-Gonzalez MA, Bes-Rastrollo M, Serra-Majem L, Lairon D, Estruch $\mathrm{R}$, Trichopoulou A. Mediterranean food pattern and the primary prevention of chronic disease: recent developments. Nutr Rev. 2009;67:S111-6.

91. Estruch R, Martínez-González MA, Corella D, Salas-Salvadó J, Ruiz-Gutiérrez $\mathrm{V}$, Covas MI, et al. PREDIMED Study Investigators. Effects of a Mediterranean-style diet on cardiovascular risk factors: a randomized trial. Ann Intern Med. 2006;145:1-11.

92. Martínez-González MA, de la Fuente-Arrillaga C, Nunez-Cordoba JM, Basterra-Gortari FJ, Beunza JJ, Vazquez Z, et al. Adherence to Mediterranean diet and risk of developing diabetes: prospective cohort study. BMJ. 2008;336:1348-51.

93. Barton RL, Whitehead K. A review of community based healthy eating interventions. J Hum Nutr Diet. August 2008;21:378-9.

94. Rolls B, Ello-Martin JA, Tohill BC. What can intervention studies tell us about the relationship between fruit and vegetable consumption and weight management? Nutrition Reviews. 2008;62:1-17.

95. World Cancer Research Fund \& American Institute of Cancer Research. The second expert report: Food, nutrition, physical activity and the prevention of cancer - a global perspective. Part 2, Evidence and Judgements; Chapter 4. Foods and Drinks. Washington (DC): American Institute for Cancer Research; 2007. Available from URL: http://www.dietandcancerreport.org/downloads/ chapters/chapter_04.pdf (Accessed 19 August, 2009).

96. World Health Organization. Food and Agriculture Organization of the United Nations. Diet, nutrition and the prevention of chronic diseases. Report of a joint WHO/FAO expert consultation, Geneva, 28 January - 1 February 2002. WHO Technical Report Series 916. Geneva: World Health Organization; 2003. Available from http://whqlibdoc.who.int/trs/WHO_trs_916.pdf (Accessed 31 March, 2010). 
97. Woodside JV, McCall D, McGartland C, Young IS. Dietary intake vs. supplement use. Proceedings of the Nutrition Society. 2005;64:543-53.

98. Dangour AD, Sibson VL, Fletcher AE. Hormones and supplements: do they work? micronutrient supplementation in later life: limited evidence for benefit. The J Gerontol A Biol Sci Med Sci. 2004;59:B659-73.

99. Yach D, Kellogg M, Voute J. Chronic diseases: an increasing challenge in developing countries. Trans R Soc Trop Med Hyg. 2005;99:321-4.

100. European code against cancer and scientific justification: third version (2003). Europe Against Cancer. 2003. Available from URL: http://www.cancercode. org/code.htm (Accessed 31 March, 2010).

101. Fourth Joint Task Force of the European Society of Cardiology and other societies on cardiovascular disease prevention in clinical practice. European guidelines on cardiovascular disease prevention in clinical practice: full text. Eur J Cardiovasc Prev Rehabil. 2007;14 Suppl 2:S1-113.

102. U.S. Department of Health and Human Services, National Institutes of Health, National Heart Lung and Blood Institute. JNC 7 Express. The seventh report of the joint national committee on prevention, detection, evaluation and treatment of high blood pressure. NIH Publication No. 03-5233. Bethesda, MD: National heart Lung and Blood Institute: 2003.

103. Mancia G, Laurent S, Agabiti-Rosei E, Ambrosioni E, Burnier M, Caulfield MJ, et al. Reappraisal of European guidelines on hypertension management: a European Society of Hypertension Task Force document. J Hypertens. 2009; Oct 15. [Epub ahead of print].

104. National Heart, Lung and Blood Institute, National Institutes of Health, US Department of Health and Human Services. Third report of the national cholesterol education program expert panel on detection, evaluation and treatment of high blood cholesterol in adults (Adult treatment panel III). NIH Publication No. 01-3670. Washington DC: U.S. Department of Health and Human Services; 2001.

105. Markowitz LE, Dunne EF, Saraiya M, Lawson HW, Chesson H, Unger ER. Quadrivalent Human Papillomavirus vaccine: recommendations of the Advisory Committee on Immunization Practices (ACIP). MMWR Recomm Rep. 2007;56 (RR-01):1-24.

106. Mast EE, Weinbaum CM, Fiore AE, Alter MJ, Bell BP, Finelli L, et al. Comprehensive immunization strategy to eliminate transmission of hepatitis $\mathrm{B}$ virus infection in the United States. Recommendations of the Advisory Committee on Immunization Practices (ACIP) part two: immunization of adults. MMWR Morb Mort Wkly Rep. 2006;55(RR-16):1-33.

107. WHO. 2008-2013 Action Plan for the Global Strategy for the Prevention and Control of Noncommunicable Diseases. Geneva: World Health Organization, 2008.

108. Nabel EG, Stevens S, Smith R. Combating chronic disease in developing countries - partners in progress. Lancet. 2009; 373:2004-6. 
109. Van der Heyden JH, Schaap MM, Kunst AE, Esnaola S, Borrell C, Cox B, et al. Socioeconomic inequalities in lung cancer mortality in 16 European populations. Lung Cancer. 2009;63:322-30.

110. Sentell T, Halpin HA. The importance of adult literacy in understanding health disparities. J Gen Intern Med. 2006;21:862-6.

111. Messinger-Rapport B. Disparities in long-term health care. Nurs Clin North Am. 2009; 44:179-85.

112. Stuckler D, King L, Robinson H, McKee M. WHO's budgetary allocations and burden of disease: a comparative analysis. Lancet. 2008;372:1563-9.

113. Taylor S. Wealth, health and equity: convergence to divergence in late 20th century globalization. Br Med Bull. 2009;91:29-48.

114. Eurocan Plus. Feasibility study for coordination of national cancer research activities. Summary Report of the Eurocan+Plus Project. Lyon: International Agency for Research on Cancer; 2008.

115. Cassels A. Guide to sector-wide approaches for health development: Concepts, issues and working arrangements (WHO/ARA/97.12). Geneva: Division of Analysis Research and Assessment, World Health Organization; 1997.

116. Swiss Agency for Development and Cooperation. The Kyrgyz-Swiss-Swedish Health Project (KYSS). Project description. 2009; Available from URL: http://www.swiss-cooperation.admin.ch/central/index.php?\&nsvID= 220858\&IanglD=1 (Updated June, 2009 and accessed 31 March, 2010).

117. World Health Organization. The Bangkok charter: health promotion in a globalized world. Geneva: WHO; 2006. A59/21 4 May 2006. 